


\title{
MORFO-ANATOMIA CAULINAR DE NOVE ESPÉCIES DE ORCHIDACEAE
}

\author{
Virginia del Carmen Oliveira ${ }^{1}$ \\ Maria das Graças Sajo ${ }^{2,3}$
}

Recebido em 17/04/00. Aceito em 23/3/01

\begin{abstract}
RESUMO - (Morfo-anatomia caulinar de nove espécies de Orchidaceae). Foram analisados sob o ponto de vista morfo-anatômico os sistemas caulinares (caule aéreo, rizoma e pseudobulbo) de nove espécies de Orchidaceae (Catasetum fimbriatum, Dichaea bryophila, Encyclia calamara, Epidendrum campestre, Epidendrum secundum, Miltonia flavescens, Pleurothallis smithiana, Stanhopea lietzei e Vanda tricolor). Comparando-se as espécies foi possível reconhecer uma certa uniformidade na organização interna dessas estruturas. Os rizomas e caules aéreos são revestidos por epiderme unisseriada, apresentam córtex parenquimático e feixes vasculares colaterais distribuídos em dois ou mais anéis no cilindro central. Os pseudobulbos possuem epiderme unisseriada recoberta por espessa cutícula e feixes vasculares colaterais distribuídos irregularmente no tecido parenquimático fundamental, que é formado por células grandes e pequenas com grande quantidade de espaços intercelulares.
\end{abstract}

Palavras-chave - rizoma, pseudobulbo, caule aéreo, Orchidaceae

ABSTRACT - (Stem anatomy of nine Orchidaceae species). Stem morphology and anatomy of nine species of Orchidaceae (Catasetum fimbriatum, Dichaea bryophila, Encyclia calamara, Epidendrum campestre, Epidendrum secundum, Miltonia flavescens, Pleurothallis smithiana, Stanhopea lietzei and Vanda tricolor) were investigated. A comparative study of these species showed that the internal structure of the rhizome, aerial shoot and pseudobulb was homogeneous. The rhizomes and aerial shoots are covered by an uniseriated epidermis, have a parenchymatous cortex and collateral vascular bundles arranged in two or more rings in the central cylinder. The psudobulbs have an uniseriated epidermis covered by a thick cuticle and vascular bundles irregularly scattered throughout the parenchymatous ground tissue which are formed by large and small cells and have many intercelular spaces.

Key words - rhizome, pseudobulb, aerial shoot, Orchidaceae

\section{Introdução}

As Orchidaceae constituem uma das maiores famílias de plantas floríferas e representam o grupo mais evoluído da super ordem Liliiflorae, exibindo características altamente especializadas na atração de insetos, que propiciam a polinização cruzada. Embora

\footnotetext{
${ }^{1}$ Parte da dissertação de Mestrado de V.C. Oliveira

${ }^{2}$ Departamento de Botânica, IB-UNESP, Caixa Postal 199, 13506-900 Rio Claro, SP, Brasil

${ }^{3}$ Autor para correspondência: mgsajo@rc.unesp.br
} 
suas flores apresentem estrutura relativamente uniforme, a organização de seus órgãos vegetativos é bastante diversa (Dressler 1993) encontrando-se grande variedade de formas de crescimento na família (Pabst \& Dungs 1975).

Apesar de variadas, as formas de crescimento em Orchidaceae se originam fundamentalmente de ramificações monopodial ou simpodial. A ramificação monopodial se caracteriza pela presença de um único eixo caulinar, que produz folhas e cresce de forma indefinida. Nas orquídeas monopodiais, as inflorescências são geralmente axilares e as raízes são produzidas em todos os nós caulinares (Withner et al. 1974; Betchel et al. 1981). A ramificação simpodial, presente na maioria das monocotiledôneas, é considerada um padrão ancestral (Holttum 1955) e se caracteriza pela presença de vários eixos caulinares, em forma de pseudobulbos ou colmos, que se originam a partir de rizomas (Witner et al. 1974).

Os pseudobulbos são formados pelo desenvolvimento lateral de um ou mais entrenós caulinares. Apresentam formas e tamanhos variados e podem funcionar como órgãos de reserva, particularmente nas espécies epífitas (Betchel et al. 1981). Quando composto por um único entrenó, o pseudobulbo é heteroblástico e quando formado por dois ou mais entrenós ele é homoblástico; este último é considerado o tipo mais primitivo (Withner et al. 1974).

Embora as primeiras revisões sobre anatomia de Orchidaceae sejam de cunho descritivo (Solereder \& Meyer 1930), atualmente os caracteres anatômicos presentes na família têm sido analisados sob o ponto de vista ecológico/evolutivo, com o intuito de reconhecer a capacidade adaptativa de seus representantes (Withner et al. 1974; Dressler 1981). Este estudo tem como objetivo descrever e comparar a estrutura anatômica de diferentes tipos caulinares (caule aéreo, rizoma e pseudobulbo), encontrados em nove espécies de orquídeas.

\section{Material e métodos}

O material utilizado é proveniente da coleção viva de orquídeas do Instituto de Botânica de São Paulo (IBt) e se encontra registrado com a seguinte numeração: Catasetum fimbriatum Lindl. 3741, Dichaea bryophila Rchb. f. 13955, Encyclia calamara (Lindl.) Pabst 16, Epidendrum campestre Lindl. 7063, Epidendrum secundum Jacq. 4780D, Miltonia flavescens Lindl. 6473, Pleurothallis smithiana Lindl. 6073, Stanhopea lietzei (Regel) Schltr. 3469 e Vanda tricolor Lindl. 11500.

As estruturas caulinares foram fixadas em FAA 50 e posteriormente transferidas para etanol 70\% (Johansen 1940). Para a análise anatômica, foi selecionada a região mediana dos entrenós (pseudobulbos e caules aéreos) e a região mediana dos rizomas.

Os cortes histológicos, obtidos a mão livre com o auxílio de lâminas de barbear, foram corados com azul de astra e fucsina básica (Roeser 1962) e montados em gelatina glicerinada. Para a identificação do amido, utilizou-se a solução de Lugol (Bürchel 1962); da lignina, solução de floroglucina acidificada (Johansen 1940); dos lipídios, Sudan III (Johansen 1940); da sílica, cristais de fenol (Johansen 1940) e dos flavonóides, hidróxido de potássio (Costa 1982).

Os desenhos de hábito foram confeccionados a partir de exemplares vivos e os resultados anatômicos registrados através fotomicrografias, obtidas em fotomicroscópio Olympus.

\section{Resultados e discussão}

Algumas das espécies estudadas apresentam o caule aéreo conspícuo e lenhoso, como 
Vanda tricolor (Fig. 2) e Epidendrum secundum (Fig. 4); em outras, como Pleurothallis smithiana (Fig. 1) e Dichaea bryophila (Fig. 3), o caule aéreo é pouco desenvolvido.

Em todos os casos, eles são revestidos por epiderme unisseriada contínua e cuticularizada (Fig. 10-13), sendo que em Pleurothallis smithiana (Fig. 12) e Epidendrum secundum (Fig. 13) observa-se uma camada subepidérmica de células esclerificadas. Em Vanda tricolor (Fig. 10), ocorrem 2-4 camadas subepidérmicas de células com paredes suberificadas e, internamente, uma camada de células parenquimáticas maiores e com paredes delgadas.

O córtex, formado por células parenquimáticas aproximadamente isodiamétricas, apresenta 3-4 camadas de espessura em Epidendrum secundum (Fig. 13) e é mais desenvolvido nos caules de Vanda tricolor (Fig. 10), Dichaea bryophila (Fig. 11) e Pleurothallis smithiana (Fig. 12). Nessa região, é comum a ocorrência de traços foliares (Fig. 10, 11 Tf), exceto em Pleurothallis smithiana que possui só uma folha apical (Fig. 1). No caule de Vanda tricolor encontram-se esclereídes isoladas e distribuídas de forma dispersa, na região cortical (Fig. 10, setas). Não existe uma delimitação morfológica nítida entre as regiões cortical e vascular.

Os feixes vasculares concentram-se na região medular em Vanda discolor (Fig. 10), Dichaea bryophila (Fig. 11) e Pleurothallis smithiana (Fig. 12) e ocupam posição periférica em Epidendrum secundum (Fig. 13). Podem se apresentar totalmente envolvidos por células esclerificadas (Fig. 12) ou possuir células esclerificadas apenas na região adjacente ao floema (Fig 13-14). Em Vanda tricolor, encontram-se também 1-2 camadas de células esclerificadas separando o xilema do floema (Fig. 14).
$\mathrm{Na}$ região central de todos os caules aéreos, é comum a presença de células parenquimáticas com amiloplastos (Fig. 12). Epidendrum secundum (Fig. 4), além de uma região caulinar aérea, apresenta também um rizoma curto. Comparando-se a a região cortical, nos dois tipos morfológicos caulinares, nota-se que no rizoma ela é mais conspícua (Fig. 15) do que na porção aérea do caule (Fig. 13), como observado para outras Orchidaceae também portadoras dessas formas caulinares (Rosso 1966).

Os rizomas são distintos em Catasetum fimbriatum (Fig. 5), Epidendrum campestre (Fig. 6), Stanhopea lietzei (Fig. 7), Encyclia calamara (Fig. 8) e Miltonia flavescens (Fig. 9), que são espécies simpodiais portadoras de pseudobulbos.

Todos os rizomas são revestidos por epiderme unisseriada e cuticularizada (Fig. 15, 17, 1921); em Encyclia calamara, entretanto, a cutícula é bastante espessada (Fig. 20). Em Epidendrum secundum nota-se uma camada subepidérmica de células esclerificadas (Fig. 15), como em outras espécies epífitas (Withner et al. 1974).

A região cortical é bem definida, formada por 11-24 camadas de células parenquimáticas isodiamétricas, quando vistas em secção transversal (Fig. 15, 17, 19, 20); em Stanhopea lietzei, ocorrem esclereídes isoladas, distribuídas de forma dispersa nessa região (Fig. 21, 22). No cilindro central, observam-se feixes vasculares colaterais (Fig. 16, 18, 19-20) com várias camadas de células esclerificadas, adjacentes ao floema (Fig. 16, 18-20, 23)

Em todas as espécies, as células parenquimáticas do rizoma frequentemente contêm amiloplastos (Fig. 23), como observado em outros representantes da família (Rosso 1966; Scatena \& Nunes 1996). Segundo Holttum (1955), o amido é usado para crescimentos periódicos do órgão e para a formação de novas ramificações. 


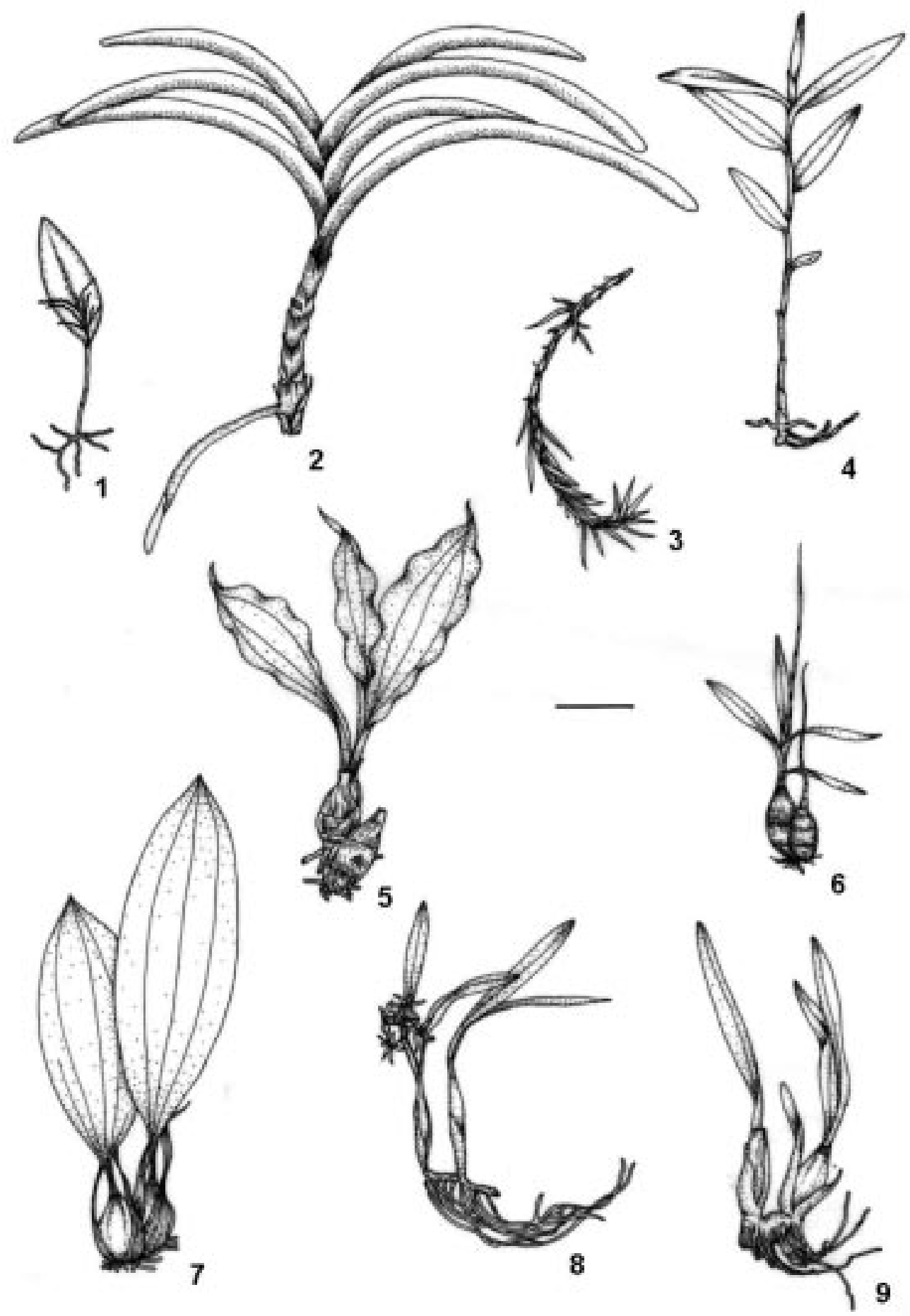

Figuras 1-9. Aspecto geral. 1. Pleurothallis smithiana; 2. Vanda tricolor; 3. Dichaea bryophila; 4. Epidendrum secundum; 5. Catasetum fimbriatum; 6. Epidendrum campestre; 7. Stanhopea lietzei; 8. Encyclia calamara; 9. Miltonia flavescens. $($ Barra $=5 \mathrm{~cm})$. 


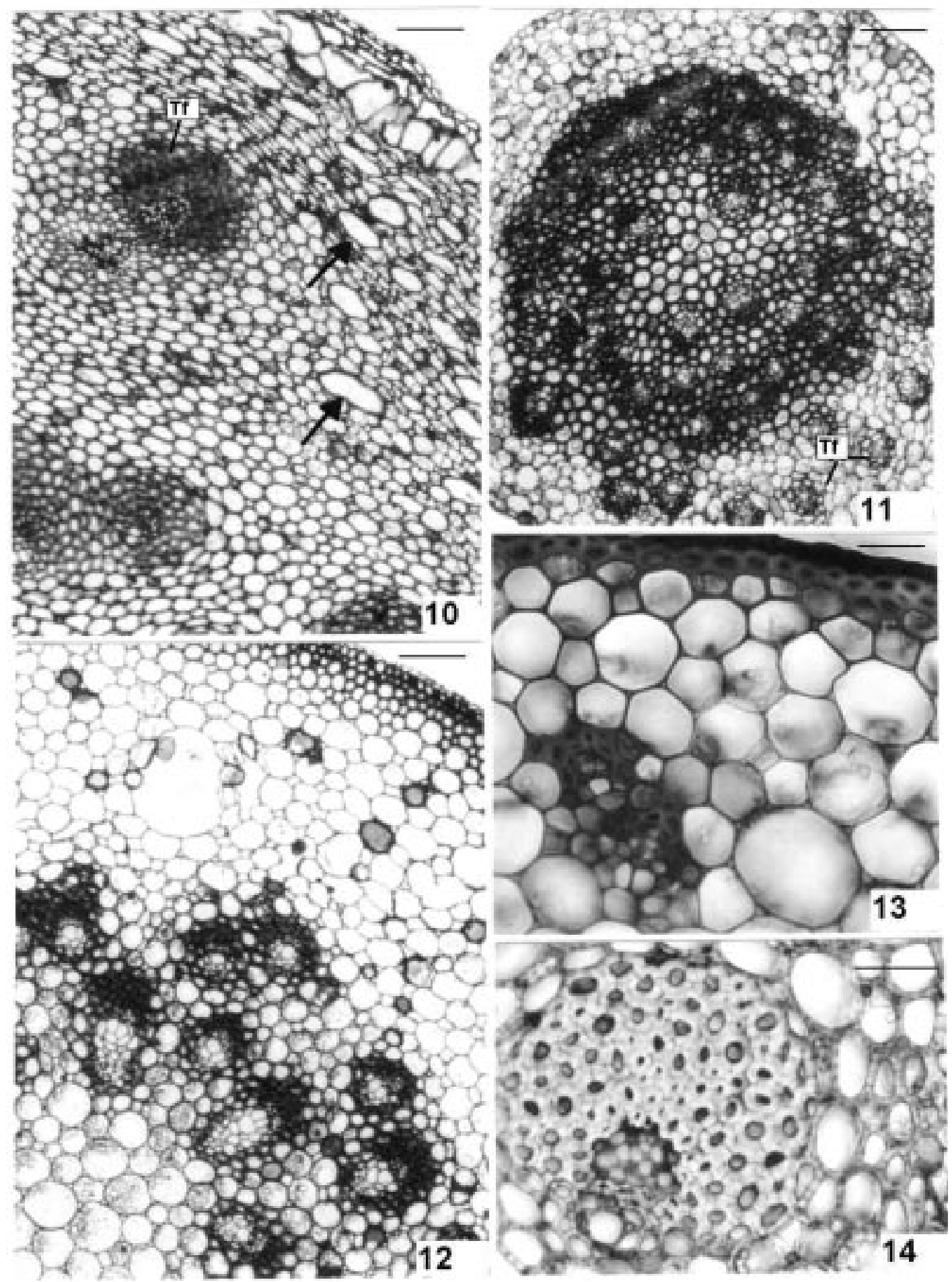

Figuras 10-14. Aspecto geral de cortes transversais de caules aéreos. 10. Vanda tricolor. As setas indicam esclereídes; 11. Dichaea bryophila; 12. Pleurothallis smithiana; 13. Epidendrum secundum; 14. Detalhe de um feixe vascular do caule de Vanda tricolor, em corte transversal. Tf - traço foliar. (Barra: 10-12 = $125 \mathrm{~mm} ; 13-14=50 \mathrm{~mm}$ ). 


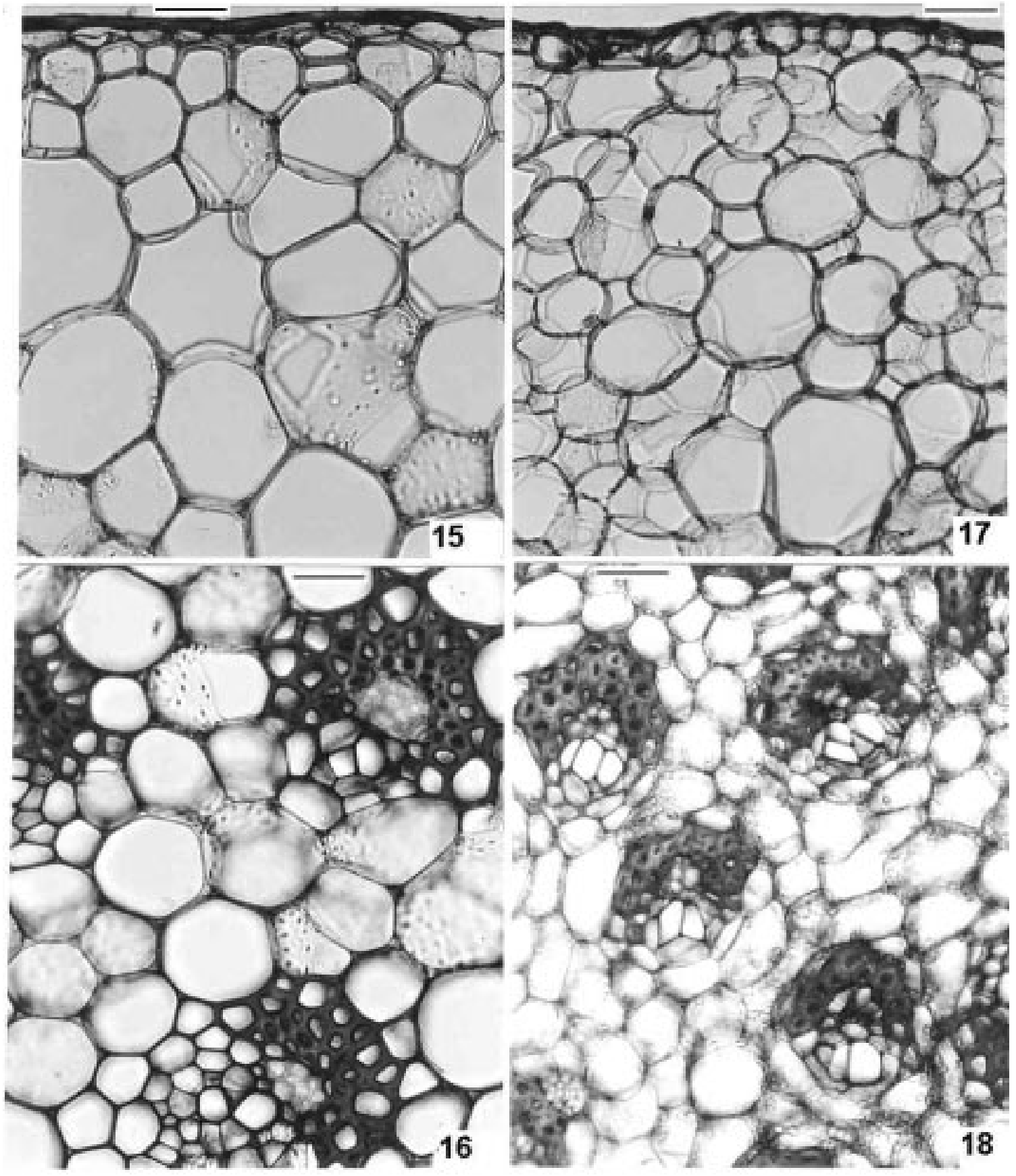

Figuras 15-18. Aspecto geral de cortes transversais de rizomas. 15-16. Epidendrum secundum, mostrando região cortical e medular, respectivamente; 17-18. Epidendrum campestre, mostrando região cortical e medular, respectivamente. $(\mathrm{Barra}=50 \mathrm{~mm})$. 


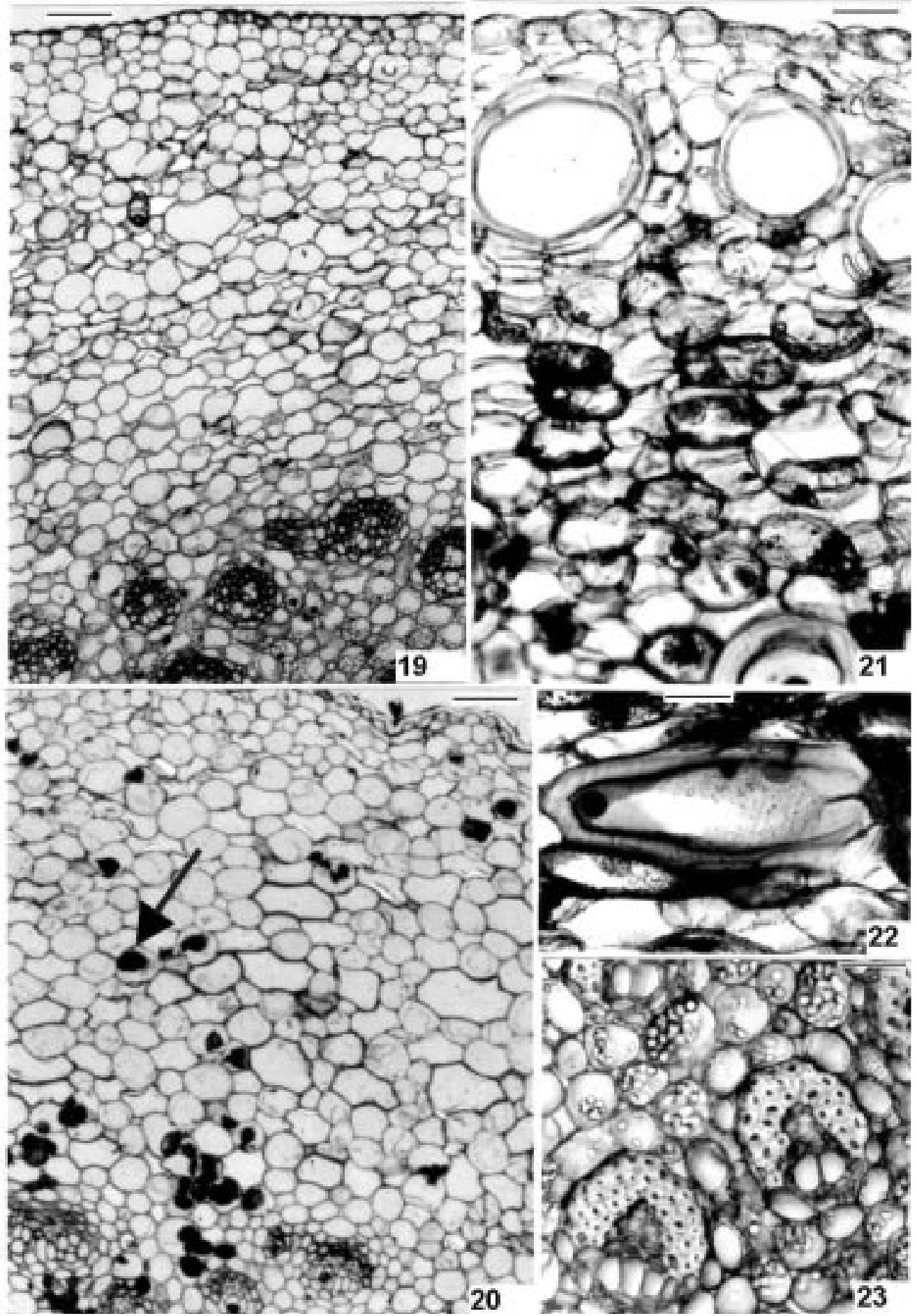

Figuras 19-23. Rizomas. 19. Catasetum firiatum - aspecto geral em corte transversal; 20. Encyclia calamara - aspecto geral em corte transversal. As setas indicam cristais flavonoídicos; 21. Stanhopea lietzei - detalhe da região cortical em corte transversal; 22. Stanhopea lietzei - detalhe de uma esclereíde, presente no córtex do rizoma em corte longitudinal; 23. Detalhe de um feixe vascular presente no rizoma de Miltonia flavescens. (Barra: 19-20 = $125 \mathrm{~mm} ; 21-23=50 \mathrm{~mm}$ ). 
No rizoma de Encyclia calamara ocorrem cristais de natureza flavonoídica, tanto na região da medula como no parênquima cortical (Fig. 20, setas). Os flavonóides, além de funcionar contra a herbivoria, associam-se aos radicais livres, frequentes em plantas que vivem sob algum tipo de estresse (Yamasaki et al. 1997), neste caso o hídrico.

Da mesma forma que nos caules aéreos, a região cortical dos rizomas não é delimitada da região central pela presença de um anel esclerenquimático definido, como em outras espécies da família (Pridgeon \& Williams 1979; Pridgeon 1982; Scatena \& Nunes 1996). Embora Rosso (1966) e Scatena \& Nunes (1996) tenham reconhecido endoderme e periciclo nos rizomas por eles estudados, a zona limítrofe entre córtex e cilindro central é representada apenas por uma maior concentração de feixes vasculares, sem ocorrência clara de endoderme, nos rizomas examinados no presente estudo (Fig. 19).

Em Catasetum fimbriatum (Fig. 5), Epidendrum campestre (Fig. 6), Stanhopea lietzei (Fig. 7), Encyclia calamara (Fig. 8) e Miltonia flavescens (Fig. 9) ocorrem pseudobulbos. Os pseudobulbos, freqüentes em epífitas da família (Braga 1977, 1987), são segmentos caulinares dilatados e verticais de onde, comumente, surgem folhas (Fig. 5-9). Eles podem ser achatados (Fig. 7), ovóides (Fig. 5, 6 e 9) ou fusiformes (Fig. 8) e constituir estruturas homoblásticas (Fig. 56) ou heteroblásticas (Fig. 7-9).

Entretanto, sua estrutura anatômica é bastante similar: são revestidos por epiderme unisseriada, desprovida de tricomas/ estômatos e recoberta por cutícula espessada (Fig. 24-25). Internamente são formados por tecido parenquimático onde se encontram distribuídos numerosos feixes vasculares colaterais (Fig. 24). Como nos caules aéreos e rizomas, não se verifica um limite definido entre córtex e cilindro vascular.
Em Catasetum fimbriatum (Fig. 26) e Stanhopea lietzei (Fig. 27-29), a epiderme do pseudobulbo é formada por células de paredes fortemente espessadas, em corte transversal (Fig. 26, 28), e que em vista frontal mostram paredes espessadas e onduladas (Fig. 2829), como observado em Eria braccata (Orchidaceae) por Khasim \& Mohana Rao (1990). Em Stanhopea lietzei, ocorrem numerosas pontoações nas paredes das células epidérmicas (Fig. 26).

A região subepidérmica dos pseudobulbos é formada por 1-2 camadas de células poligonais arredondadas (Fig. 24-25) e as células do parênquima fundamental são de tamanho e forma variadas: ocorrem células pequenas de paredes pontoadas (Fig. 25, seta), ao lado de células maiores. Em todos os pseudobulbos, as células pequenas comumente reservam amido, enquanto que as grandes armazenam água. Estas últimas são globosas, hialinas e suas paredes podem ser destituídas de espessamento, como em Miltonia flavescens, Stanhopea lietzei e Epidendrum campestre (Fig. 25), ou apresentar espessamento secundário, como em Catesetum fimbriatum e Encyclia calamara (Fig. 32, seta). Neste caso, as células são semelhantes às presentes em folhas de Orchidaceae (Foster 1956; Olatunji \& Nengim 1980; Pridgeon 1982; Bonates 1993; Scatena \& Nunes 1996; Oliveira \& Sajo 1999a) e de algumas Agavaceae (Koller \& Rost 1988). São, também, similares às encontradas no córtex das raízes de Pleurothallis smithiana, Catasetum fimbriatum e Stanhopea lietzei (Oliveira \& Sajo 1999b) e ocorrem, ainda, em pseudobulbos de epífitas africanas (Olatunji \& Nengim 1980). Foram descritas como elementos traqueoidais, cuja função é reter água e oferecer suporte mecânico, evitando o colapso celular durante a dessecação (Olatunji \& Nengim 1980).

Envolvendo os feixes vasculares, observa-se uma bainha parenquimática formada por 1-3 


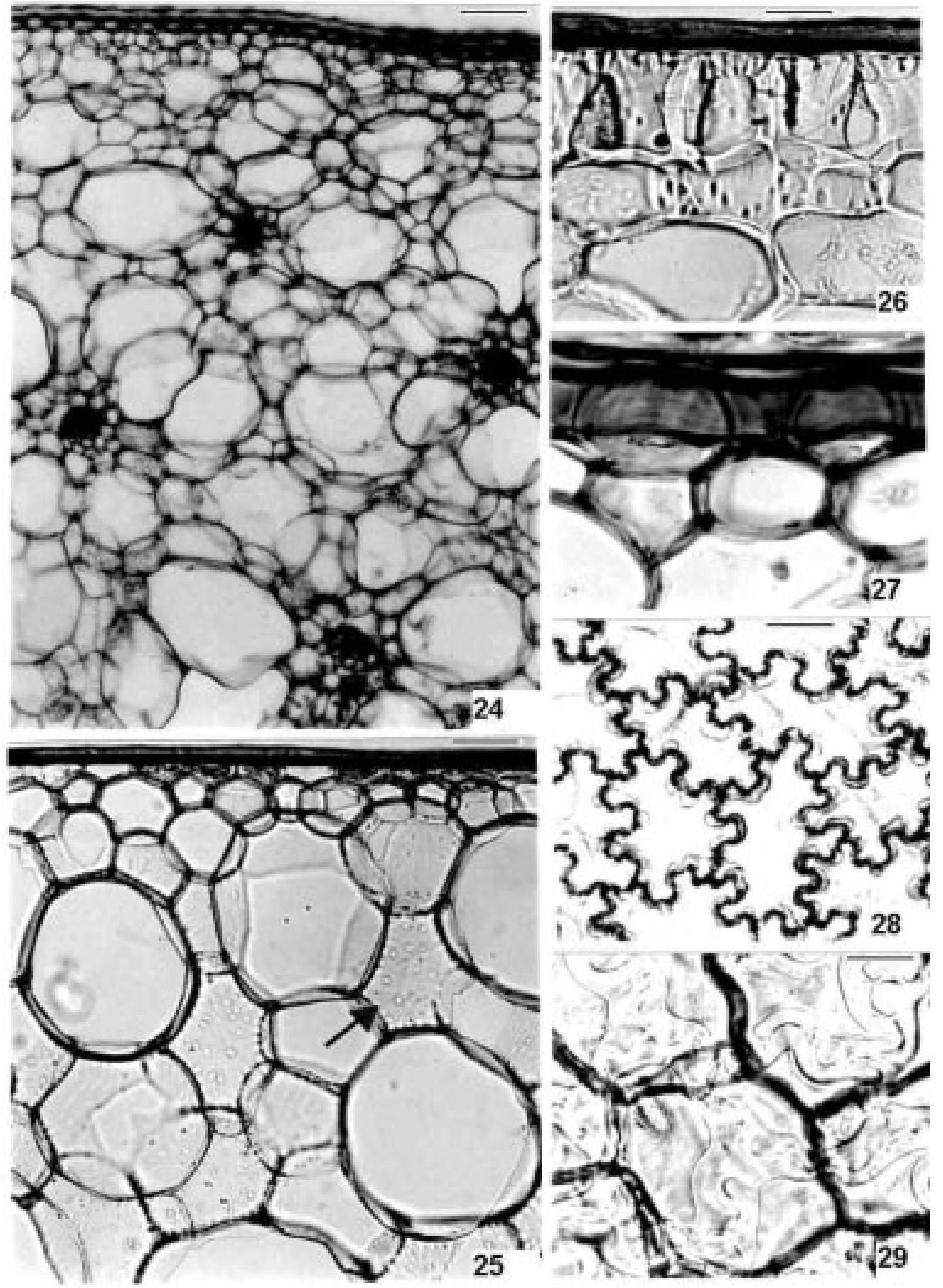

Figuras 24-29. Pseudobulbos. 24. Miltonia flavescens - aspecto geral em corte transversal; 25. Epidendrum campestre aspecto geral da região cortical. A seta indica célula com parede pontoada; 26. Stanhopea lietzei - detalhe da epiderme em corte transversal, mostrando células de paredes espessadas e pontoadas; 27-29. Epiderme de Catasetum fimbriatum; 27. Vista transversal mostrando células de paredes espessadas recobertas por espessa cutícula; 28. Vista frontal das paredes periclinais externas onduladas; 29. Vista frontal das paredes periclinais internas fortemente espessadas e onduladas. (Barra: $24=125 \mathrm{~mm}$; $25-26$ e $28=50 \mathrm{~mm} ; 27$ e $29=25 \mathrm{~mm}$ ). 

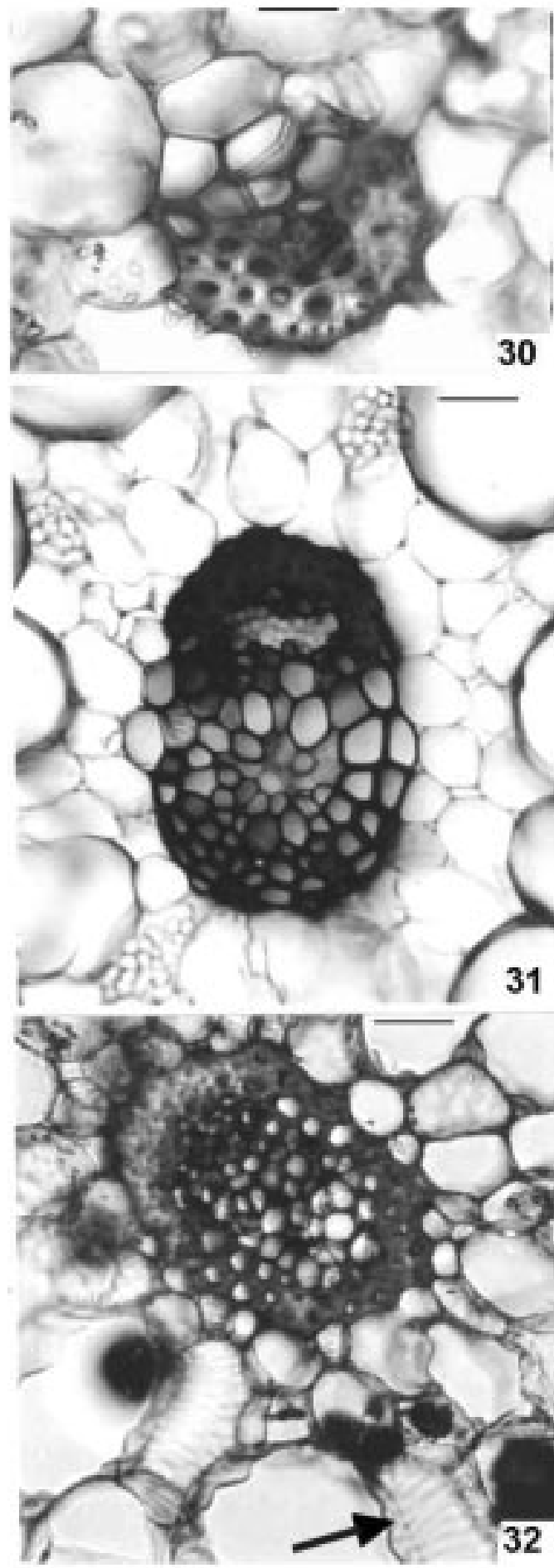

Figuras 30-32. Detalhes de feixes vasculares de pseudobulbos em corte transversal. 30. Miltonia flavescens, mostrando estegmatas associadas às fibras (seta). 31. Miltonia flavescens, mostrando células parenquimáticas portadoras de grãos de amido associadas ao feixe vascular. 32. Encyclia calamara, mostrando células com espessamento secundário (seta) e compostos flavonoídicos nas adjacências do feixe. (Barra: $30=25 \mathrm{~mm} ; 31-32=50 \mathrm{~mm}$ ). 
camadas de células, geralmente contendo amido (Fig. 31). Nos pseudobulbos de Encyclia calamara notam-se, também, cristais de natureza flavonoídica (Fig. 32) como observado no rizoma, na raiz (Oliveira \& Sajo 1999b) e nas folhas (Oliveira \& Sajo 1999a) dessa mesma espécie.

A ocorrência de elementos traqueoidais e de grande quantidade de amido, nos pseudobulbos estudados, corrobora as observações de Haberlandt (1914), Pridgeon (1986), Stern \& Morris (1992) e Zimmerman (1990) para quem os pseudobulbos, além de funcionar como órgãos de reserva, desempenham um importante papel na tolerância à seca, especialmente nas orquídeas epífitas.

Nos pseudobulbos estudados ocorrem, proporcionalmente, menos feixes vasculares do que nos rizomas. Withner et al. (1974) observaram que os rizomas contêm cerca de quatro vezes mais feixes vasculares do que os pseudobulbos, e interpretaram esse fato como uma das razões para o aspecto lenhoso desses órgãos, quando comparado com a relativa maciez dos pseudobulbos.

Como em outras Orchidaceae (Moller \& Rasmussen 1984; Stern \& Morris 1992), são frequentes nos pseudobulbos estudados estegmatas com corpos cônicos de sílica, associadas aos feixes vasculares (Fig. 30, seta). Embora o papel da sílica não se encontre bem estabelecido, estegmatas são frequentes em orquídeas epífitas xerófitas e ausentes em orquídeas terrestres mesófitas, evidenciando alguma relação entre xerofitismo e sílica (Moller \& Rasmussen 1984).

Dentre as espécies estudadas, Vanda discolor é a única com caule aéreo lenhoso. A ocorrência nesse órgão de muitos elementos mecânicos (esclereídes corticais e fibras envolvendo os feixes vasculares) pode explicar o porte desenvolvido da espécie.

Os caules aéreos de Pleurothallis smithiana, Epidendrum secundum possuem uma camada subepidérmica de células esclerificadas, que oferece sustentação ao órgão, mantendo-o ereto; já em Dichaea bryophila, com caule aéreo pendente, não se observam estruturas de sustentação.

Os rizomas estudados apresentam elementos mecânicos variados (cutícula espessada, camadas subepidérmicas de células esclerificadas, esclereídes corticais e células esclerificadas envolvendo os feixes vasculares), conferindo a esses órgãos um aspecto lenhoso. Também é comum a ocorrência de amido, provavelmente relacionado com o crescimento vegetativo da planta.

Já os pseudobulbos exibem características relacionadas à retenção de água, elemento escasso em ambientes epifíticos onde vivem as espécies estudadas. Todos eles possuem cutícula espessada, e células armazenadoras de água, que conferem ao órgão um aspecto suculento; possuem, também, uma grande quantidade de amido sugerindo uma possível função de armazenamento, conforme sugerido por Haberlandt (1914), Pridgeon (1986), Stern \& Morris (1992) e Zimmerman (1990).

\section{Agradecimentos}

Os autores agradecem ao Dr. Fábio de Barros por ter fornecido e identificado o material. Virginia C. Oliveira agradece o apoio da CAPES (Bolsa de Mestrado) e Maria das Graças Sajo agradece o apoio do CNPq (Bolsa de Produtividade em Pesquisa).

\section{Referências bibliográficas}

Betchel, H.; Cribb, P. \& Saunert, E. 1981. The manual of cultivated orchid species. MIT Press, Cambridge.

Bonates, L. C. M. 1993. Estudos ecofisiológicos de Orchidaceae da Amazônia II. Anatomia ecológica foliar de espécies com metabolismo CAM de uma campina da Amazônia central. Acta Amazonica 23(4): 315-348. 
Braga, P. I. S. 1977. Aspectos biológicos das Orchidaceae de uma campina da Amazônia Central. Acta Amazonica 7(2): 1-89.

Braga, P. I. S. 1987. Orquídeas. Biologia floral. Ciência Hoje 5(28): 53-55.

Bücherl, W. 1962. Técnica Microscópica. Editora Polígono, São Paulo.

Costa, A. F. 1982. Farmacognosia. Fundação Calouste Gulbenkian, Lisboa.

Dressler, R. L. 1981. The Orchids: Natural History and Classification. Harvard University Press, Cambridge.

Dressler, R. L. 1993. Phylogeny and Classification. Deoscorides Press, Oregon.

Foster, A. S. 1956. Plant idioblasts: a remarkable example of cell specialization. Protoplasma 6: 184-193.

Haberlandt, G. F. J. 1914. Physiological plant anatomy. Macmillan Co, London.

Holttum, R. 1955. Growth habitats of monocotyledons: variations on a theme. Phytomorphology 5: 399-413.

Johansen, D. A. 1940. Plant microtechnique. Mc Graw Hill, New York.

Khasim, S. M. \& Mohana Rao, P. R. 1990. Anatomy in relation to taxonomy in some members of Epidendroideae

(Orchidaceae). Phytomorphology 40(3-4): 243-250.

Koller, A. L. \& Rost, T. L. 1988. Structural analysis of water-storage tissue in leaves of Sansevieria (Agavaceae). Botanical Gazete 149 (3): 260-274.

Mqller, J. D. \& Rasmussen, H. 1984. Stegmata in Orchidales: character state distribution and polarity. Botanical Journal of the Linnean Society 89: $53-76$.

Olatunji, O. A. \& Nengim, R. O. 1980. Occurrence and distribution of tracheoidal elements in the Orchidaceae. Botanical Journal of the Linnean Society 80: 357-370.

Oliveira, V. C. \& Sajo, M. G. 1999a. Anatomia foliar de espécies epífitas de Orchidaceae. Revista brasilileira de Botânica 22(3): 365-374.

Oliveira, V. C. \& Sajo, M. G. 1999b. Root anatomy of nine Orchidaceae species. Brazilian Archieves of Biology and Technology 42(4): 405-413.

Pabst, G. F. J. \& Dungs, F. 1975. Orchidaceae Brasiliensis I. Brucke-Verlag, Hildesheim.

Pridgeon, A. M. 1982. Diagnostic anatomical characters inthe Pleurothallidinae (Orchidaceae). American Journal of Botany 69(6): 921-938.

Pridgeon, A. M. 1986. Anatomical adaptations in Orchidaceae. Lindleyana 1(2): 90-101.
Pridgeon, A. M. \& Williams, N. H. 1979. Anatomical aspects of Dresslerella (Orchidaceae). Selbyana 5(2): 120-134.

Roeser, K. R. 1962. Die nadel der schwarzkiefer massenprodukt und kunstwerk der natur. Mikrokosmos 61(2): 33-36.

Rosso, S. W. 1966. The vegetative anatomy of the Cypripedioideae (Orchidaceae). Journal of the Linnean Society (Botany) 59: 309-341.

Scatena, V. L. \& Nunes, A. C. 1996. Anatomia de Pleurothallis rupestris. Lindl. (Orchidaceae) dos campos rupestres. Boletim de Botânica da Universidade de São Paulo 15: 35-43.

Solereder H. \& Meyer, F. 1930. Systematiche anatomie der Monokotyledonem. Verlag von Gebruder Borntraeger, Berlin.

Stern, W. L. \& Morris, M. W. 1992. Vegetative anatomy of Stanhopea (Orchidaceae) with special reference to pseudobulb water-storage cells. Lindleyana 7(1): 34-53.

Withner, C. L.; Nelson, P. K. \& Wwjksnora, P. J. 1974. The anatomy of orchids. Pp. 267-334. In: C.L. Withner (Ed.), The orchids: scientific studies. John Wiley Co, New York.

Yamasaki, H.; Sakihama, Y. \& Ikehara, N. 1997. Flavonoid-peroxidase reaction as detoxification mechanism of plant cell against $\mathrm{H}_{2} \mathrm{O}_{2}$. Plant Physiology 19(4): 481-486.

Zimmerman, J. K. 1990. Role of pseudobulbs in growth and flowering of Catasetum viridiflavum (Orchidaceae). American Journal of Botany 77(4): $533-54$ 